\title{
BMJ Open Training and education of healthcare workers during viral epidemics: a systematic review
}

\author{
Leizl Joy Nayahangan (D , ${ }^{1}$ Lars Konge, ${ }^{1,2}$ Lene Russell, ${ }^{1,3}$ Steven Andersen ${ }^{1,4,5}$
}

\begin{abstract}
To cite: Nayahangan LJ, Konge L, Russell L, et al. Training and education of healthcare workers during viral epidemics: a systematic review. BMJ Open 2021;11:e044111. doi:10.1136/ bmjopen-2020-044111
\end{abstract}

- Prepublication history and additional supplemental material for this paper are available online. To view these files, please visit the journal online (http://dx.doi.org/10.1136/ bmjopen-2020-044111).

Received 23 August 2020 Accepted 11 May 2021

\section{A Check for updates}

(C) Author(s) (or their employer(s)) 2021. Re-use permitted under CC BY-NC. No commercial re-use. See rights and permissions. Published by BMJ.

${ }^{1}$ Copenhagen Academy for Medical Education and Simulation (CAMES), Centre for Human Resouces and Education, The Capital Region of Denmark, Copenhagen, Denmark ${ }^{2}$ Department of Clinical Medicine, University of Copenhagen, Copenhagen, Denmark

${ }^{3}$ Department of Intensive Care, Rigshospitalet, Copenhagen, Denmark

${ }^{4}$ Department of

Otorhinolaryngology—Head \& Neck Surgery, Rigshospitalet, Copenhagen, Denmark ${ }^{5}$ Department of Otolaryngology, Ohio State University, Columbus Ohio, USA

\section{Correspondence to}

Leizl Joy Nayahangan;

leizl.joy.nayahangan@regionh. $\mathrm{dk}$

\section{ABSTRACT}

Background It is necessary to train a large number of healthcare workers (HCW) within a limited time to ensure adequate human resources during an epidemic. There remains an urgent need for best practices on development and implementation of training programmes.

Objective To explore published literature in relation to training and education for viral epidemics as well as the effect of these interventions to inform training of HCW. Data sources Systematic searches in five databases performed between 1 January 2000 and 24 April 2020 for studies reporting on educational interventions in response to major viral epidemics.

Study eligibility criteria All studies on educational interventions developed, implemented and evaluated in response to major global viral outbreaks from 2000 to 2020.

Participants Healthcare workers. Interventions Educational or training interventions. Study appraisal and synthesis methods Descriptive information were extracted and synthesised according to content, competency category, educational methodology, educational effects and level of educational outcome. Quality appraisal was performed using a criterion-based checklist.

Results A total of 15676 records were identified and 46 studies were included. Most studies were motivated by the Ebola virus outbreak with doctors and nurses as primary learners. Traditional didactic methods were commonly used to teach theoretical knowledge. Simulation-based training was used mainly for training of technical skills, such as donning and doffing of personal protective equipment. Evaluation of the interventions consisted mostly of surveys on learner satisfaction and confidence or tests of knowledge and skills. Only three studies investigated transfer to the clinical setting or effect on patient outcomes.

Conclusions and implications of findings The included studies describe important educational experiences from past epidemics with a variety of educational content, design and modes of delivery. High-level educational evidence is limited. Evidence-based and standardised training programmes that are easily adapted locally are recommended in preparation for future outbreaks.

\section{INTRODUCTION}

Global-scale infectious diseases engender threat, vulnerability and risk to health and

\section{Strengths and limitations of this study}

- Inclusion of educational interventional studies in the last 20 years, providing an overview of currently published training programmes for healthcare workers and evidence of educational impact.

- Systematic search of five academic databases according to the Preferred Reporting Items for Systematic Reviews and Meta-Analyses guidelines.

- Final inclusion of 46 studies reporting on educational interventions implemented in response to SARS Middle East respiratory syndrome, Ebola virus disease and COVID-19.

- Exclusion of descriptive studies reporting on development of training programmes without evaluation and studies reporting on organisational outcomes with no relevance to training nor evaluation of educational effects.

- Important educational efforts not described in published form were not included.

healthcare capacity as well as the economic and political stature of a nation. ${ }^{1}$ In the last 20 years, the world has seen several major epidemic outbreaks caused by viral agentsnamely SARS in 2003, ${ }^{2}$ swine influenza (H1N1 influenza virus infection) ${ }^{3}$ in 2009-2019, Middle East respiratory syndrome (MERS) in 2012, ${ }^{4}$ and Ebola virus disease (EVD) in 2014$2016 .{ }^{5}$ Currently, the entire world is facing a pandemic with a COVID- $19,{ }^{6}$ a new and fast spreading viral agent that can challenged and even overwhelm healthcare delivery and capacity as well as human resources. These viral outbreaks have prompted the need for global communities to swiftly plan, prepare and ensure continuous healthcare functionality, resource availability and skilled manpower to increase surge capacity. ${ }^{7}$

Healthcare professionals from across different areas were called to help and needed to learn new procedures including correct use of personal protective equipment (PPE) ${ }^{8}$ and management of critically ill patients on ventilatory support. ${ }^{9}$ To ensure adequate resources and staffing, it was necessary to quickly train 
a large number of healthcare workers (HCW) to be on the frontlines. Ideally, training and education in preparation for a new infectious threat should be continuous and planned ahead of time. Specialised training equips HCW with the knowledge and skills to safely provide patient care; to reduce fatalities during an outbreak; and to prevent and control nosocomial infections. ${ }^{10-12}$

The experiences learnt from previous viral epidemics have helped some countries such as China and Saudi Arabia to deal with and respond to the current COVID-19 pandemic. ${ }^{13}{ }^{14}$ However, this is not always the case: some countries that ranked high in the preparedness for pandemics assessed via the Global Health Security Index showed inconsistencies with their actual performance during the current COVID-19 pandemic. ${ }^{15}$ While there are key capacities that were considered in this performance assessment, the current pandemic has highlighted the need to increase the number of sufficiently trained HCW. ${ }^{16}$ There remains an urgent need for best practices on development and implementation of training programmes during an epidemic.

In this systematic review, we sought to answer three specific research questions:

1. What are the educational content and types of competencies being trained in relation to HCW as a result of a major viral epidemic?

2. How can training be delivered under these conditions?

3. What are the reported effects of the training interventions?

The overall aim of the study was to provide an overview of the published literature in relation to training and education of HCW during viral epidemics and to explore the educational content of these interventions and the level of competencies being trained. We also sought to present a status on the evidence of effects of these training interventions.

\section{METHODS}

This systematic review was conducted and reported in adherence with the Preferred Reporting Items for Systematic Reviews and Meta-analyses guideline. ${ }^{17}$

\section{Study eligibility}

We considered all studies on educational or training interventions developed, evaluated and/or implemented in response to major global viral outbreaks transmitted via close person-to-person contact from 2000 to 2020: SARS, H1N1, MERS, EVD and COVID-19. Inclusion criteria included studies reporting on development, implementation and evaluation of educational interventions for HCW, while the exclusion criteria were studies that were not in English language, descriptive studies, and those reporting on organisational outcomes with no relevance to training nor any outcome measures to evaluate the effect of training (table 1).

\section{Search strategy}

The search strategy was designed to access published literature in health professions education and clinical journals.
Table 1 Inclusion and exclusion criteria for inclusion in a systematic review on training and education of healthcare workers during viral epidemics

\begin{tabular}{ll}
\hline Inclusion criteria & Exclusion criteria \\
\hline Population: Healthcare & Studies that were not in \\
professionals, healthcare & English language. \\
workers and healthcare & Unpublished literature \\
students at any level. & or not available through \\
Intervention: Studies & online access. \\
reporting on the & Abstracts with insufficient \\
development, evaluation & description, quantitative or \\
and implementation of & qualitative data \\
educational interventions & Descriptive papers \\
regarding treatment and & that only describe \\
prevention control. & development of the \\
Comparison: Any studies & educational intervention \\
investigating educational & without any evaluation. \\
interventions. & Studies reporting on \\
Outcomes: Studies & organisational outcomes \\
with learner outcome & with no relevance to \\
measures. & training nor evaluation of \\
Design: Any quantitative & educational or training \\
or qualitative interventional & effects. \\
study. & \\
Context: Studies & \\
conducted in any & \\
healthcare or healthcare & \\
professions educational & \\
setting. & \\
\hline
\end{tabular}

Five databases were searched from 1 January 2000 to 24 April 2020 (PubMed, Excerpta Medica (EMBASE)/Ovid, Cochrane Library, Web of Science and Directory of Open Access Journals) using the search terms (training OR educat* OR teach*) AND (coronavirus OR SARS OR H1N1 OR MERS OR EBOLA OR COVID-19). See table 2 for full search details.

\section{Study selection}

The search results were retrieved and imported into the Mendeley software (London, UK). Two authors (LJN and SA) independently reviewed and screened titles and abstracts, and eligible studies were included for full-text screening using Covidence (Veritas Health Innovation, Melbourne, Australia). The same reviewers independently screened the studies for eligibility and final inclusion. Disagreements were resolved with the remaining co-authors.

\section{Data extraction and synthesis}

A data extraction form was developed in REDCap (Vanderbilt University, USA) and was piloted with five randomly selected studies. Discrepancies in extraction and analysis by the two reviewers were discussed and the form was revised. The following details were extracted: general study information including study design; viral illness; target learner population and learner level; competency category; educational modality; description of intervention; description of educational 
Table 2 Search strings used in a systematic review on training and education of healthcare workers during viral epidemics

\begin{tabular}{|c|c|}
\hline PubMed & $\begin{array}{l}\text { (training OR educat* OR teach*) AND } \\
\text { (coronavirus OR SARS OR H1N1 OR MERS } \\
\text { OR EBOLA OR COVID-19) }\end{array}$ \\
\hline Cochrane & $\begin{array}{l}\text { ID Search } \\
\text { \#1 TRAINING } \\
\text { \#2 educat* } \\
\text { \#3 teach* } \\
\text { \#4 coronavirus } \\
\text { \#5 SARS } \\
\text { \#6 H1N1 } \\
\text { \#7 MERS } \\
\text { \#8 EBOLA } \\
\text { \#9 COVID-19 } \\
\text { \#10 \#1 OR \#2 OR \#3 } \\
\text { \#11 \#4 OR \#5 OR \#6 OR \#7 or \#8 OR \#9 } \\
\text { \#12 \#10 AND \#11 }\end{array}$ \\
\hline EMBASE & $\begin{array}{l}\text { (training OR educat* OR teach*) AND } \\
\text { (coronavirus OR sars OR h1n1 OR mers OR } \\
\text { ebola OR 'covid 19') AND(2000-2020)/py AND } \\
\text { [english)/lim }\end{array}$ \\
\hline $\begin{array}{l}\text { Web of } \\
\text { Science }\end{array}$ & $\begin{array}{l}\text { (training OR educat* OR teach*) AND } \\
\text { (coronavirus OR SARS OR H1N1 OR MERS } \\
\text { OR EBOLA OR COVID-19) }\end{array}$ \\
\hline DOAJ & $\begin{array}{l}\text { Training AND coronavirus } \\
\text { Training AND SARS } \\
\text { Training AND H1N1 } \\
\text { Training AND MERS } \\
\text { Training AND COVID-19 } \\
\text { Training AND Ebola } \\
\text { Educat* AND coronavirus } \\
\text { Educat* AND SARS } \\
\text { Educat* AND H1N1 } \\
\text { Educat* AND MERS } \\
\text { Educat* AND EBOLA } \\
\text { Educat* AND COVID-19 } \\
\text { Teach* AND coronavirus } \\
\text { Teach* AND SARS } \\
\text { Teach* AND H1N1 } \\
\text { Teach* AND MERS } \\
\text { Teach* AND EBOLA } \\
\text { Teach* AND COVID-19 }\end{array}$ \\
\hline
\end{tabular}

DOAJ, Directory of Open Access Journals; EMBASE, Excerpta Medica; EVD, Ebola virus disease; H1N1, H1N1 influenza virus infection; MERS, Middle East respiratory syndrome.

outcomes; quality appraisal of the educational intervention in different stages (preparation, intervention and evaluation) based on a structured criterion-based checklist $^{18}$; and level of educational outcome based on Kirkpatrick's levels and education evidence. ${ }^{19}$ Synthesis was aligned with the three research questions. It was decided a priori to forego meta-analyses because of our specific research questions and expected variety of study population, interventions, context and educational outcomes.

\section{Patient and public involvement}

There were no patients nor the public that were involved in the design, or conduct, or reporting, or dissemination plans of this systematic review.

\section{RESULTS}

\section{Study selection process}

Flow chart is provided in figure 1. A total of 15676 records were identified through the searches. Of these, 10092 studies remained after removal of duplicates and studies not reported in English. Overall, 304 studies were included for full-text screening, of which 46 studies fulfilled the inclusion criteria (online supplemental table S1).

\section{Study characteristics}

Study characteristics are presented in table 3. A majority of the studies reported on learning interventions developed in response to EVD $(\mathrm{n}=24,52 \%),{ }^{20-43}$ eight studies were motivated by SARS $(17 \%),{ }^{44-51}$ seven studies by H1N1 influenza $(15 \%),{ }^{52-58}$ one study by MERS $(2 \%)^{59}$ and three studies were motivated by more than one disease ${ }^{60-62}$ Three studies were published in relation to COVID-19. ${ }^{63-65}$

The majority of the studies used a single-group study design $(\mathrm{n}=16,37 \%)$ or were educational cohort studies $(\mathrm{n}=16,35 \%)$. Two were non-randomised trials $(4 \%)^{3647}$ and six studies were randomised controlled trials $(13 \%))^{21} 4245505764$ Medical doctors and nurses were the targeted learners in most of the studies $(\mathrm{n}=18 \quad(39 \%)$ and $\mathrm{n}=25 \quad(54 \%)$, respectively). Other healthcare professionals included were for example paramedics, ${ }^{20} 59$ respiratory therapists, ${ }^{38} 5058$ pharmacists $^{435861}$ and midwives. ${ }^{3942} 43$ Students in relevant fields were included in some studies. ${ }^{28} 29484955606465$

\section{Educational content and competency category \\ Theoretical knowledge}

Thirty-five studies (76\%) reported on development of theoretical courses to educate and inform HCW regarding general principles of epidemic preparedness, disease presentation, surveillance and treatment. Resources for course content could originate from international agencies such as the WHO, from the Centers for Disease Control and Prevention ${ }^{66}$ or from official guidelines implemented by local health and infectious disease authorities to aid the hospitals. ${ }^{26}$ Knowledge on infection prevention and control (IPC) including patient care principles and safety practices were central in many of the included studies. ${ }^{23} 2733363743475160$

\section{Technical skills}

In 26 studies $(57 \%)$, the focus was on technical skills particularly on risk management strategies such as donning and doffing of PPE. $202127283136-38404352596364$ One study reported that while PPE skills can be mastered in a controlled learning environment, maintaining the 


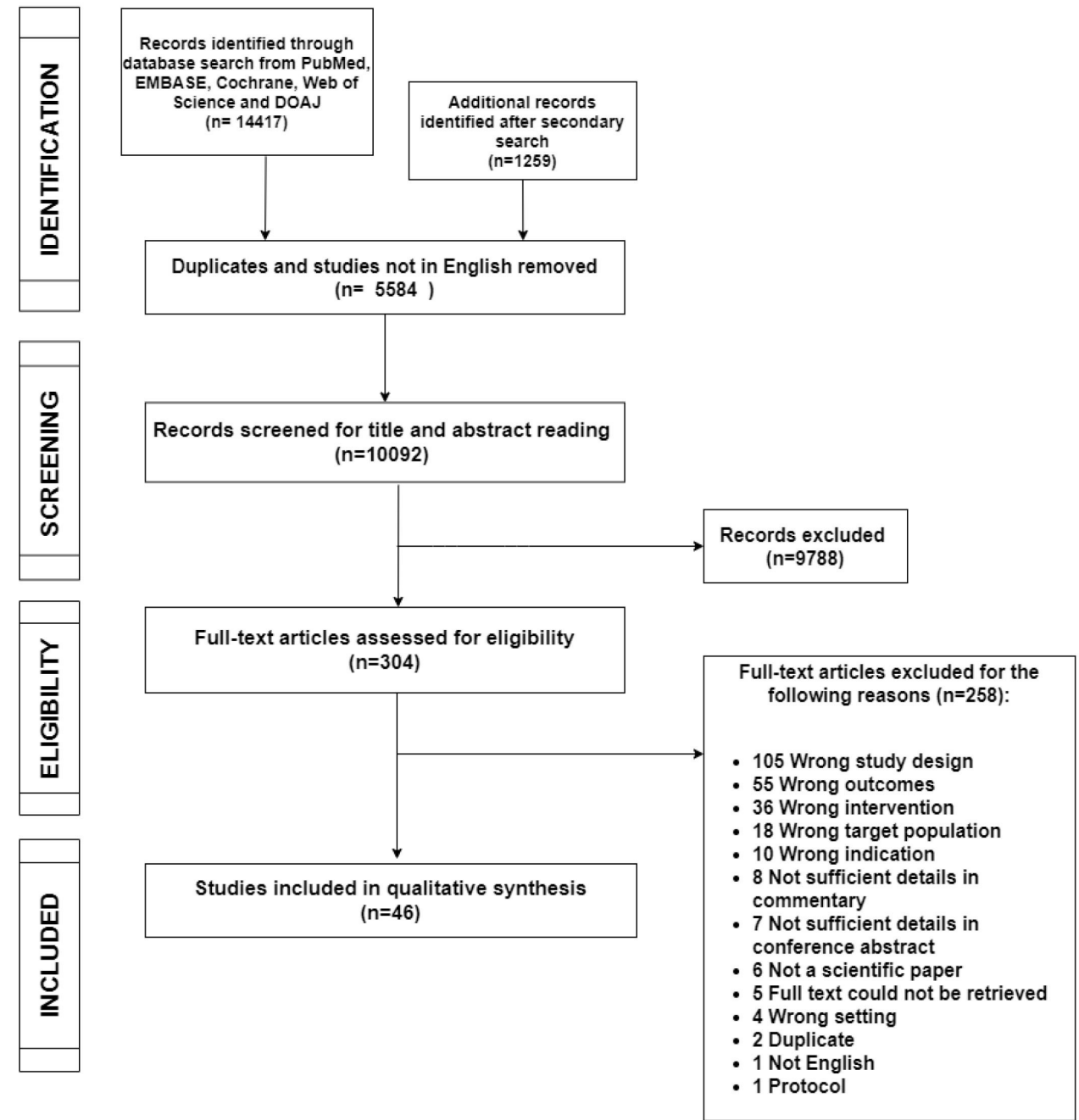

Figure 1 Preferred Reporting Items for Systematic Reviews and Meta-Analyses flowchart of the study search and selection process for a systematic review on training and education of healthcare workers during viral epidemics.

integrity of the procedure during critical situations is challenging, as well as measures to reduce risk of selfcontamination. ${ }^{20}{ }^{21}$ Critical care management skills were also often trained including endotracheal intubation, airway management techniques, manual and mechanical ventilation ${ }^{27} 386065$; advanced cardiac and airway life support (ACLS/AALS) ${ }^{44}{ }^{46}$; and extracorporeal membrane oxygenation (ECMO) management. ${ }^{5356}$

\section{'Non-technical' skills}

Eight $(17 \%)$ studies described a variety of other skills such as teamwork and cognitive load, ${ }^{21}$ interpersonal skills, reporting and decision making, ${ }^{49}$ attitude,${ }^{39}$ critical thinking skills ${ }^{61}$ concern and confidence. ${ }^{32}$ Psychological support for HCW was highlighted in three studies that designed educational interventions on psychological first aid $^{42}$ and resilience. ${ }^{57} 62$ Another study highlighted the importance of interpersonal skills for screening personnel to manage the high number of potentially anxious patients and visitors. ${ }^{49}$

\section{Training delivery}

\section{Traditional didactics}

Thirteen out of forty-six studies (28\%) used traditional didactics such as lectures and other adult learning strategies including interactive group and learner-led discussions, ${ }^{52} 5461$ case-based learning, ${ }^{29}{ }^{55}$ problem-based learning, ${ }^{48}$ demonstrations/return demonstrations ${ }^{41} 49$ and role playing. ${ }^{49}{ }^{54}$ Most of the studies that aimed to convey theoretical knowledge consisted of brief sessions, that is, less than a day $(\mathrm{n}=8 / 13,62 \%) .{ }^{414248-516162}$

\section{E-learning}

E-learning has been used to rapidly disseminate information during an epidemic outbreak. One study found that e-learning could be used to significantly increase knowledge on a prelearning and postlearning test as well as retention test. ${ }^{32}$ Other studies used CD/DVD or USB drives to disseminate course materials for self-learning, as well as audio/video mini lectures ${ }^{35} 475760$ and specific software for interactive online learning. ${ }^{36} 39$ 
Table 3 Characteristics of the educational interventional studies included in a systematic review on training and education of healthcare workers during viral epidemics

\begin{tabular}{lcc}
\hline Viral illness & $\mathbf{N}_{\text {studies }}$ & $\mathbf{N}_{\text {studies }} \mathbf{( \% )}$ \\
\hline SARS & 8 & 17 \\
H1N1 & 7 & 15 \\
\hline MERS & 1 & 2 \\
\hline EVD & 24 & 52 \\
\hline COVID-19 & 3 & 7 \\
\hline Multiple illnesses & 3 & 7 \\
Years & 1 & \\
\hline 2000-2005 & 8 & 2 \\
\hline 2006-2010 & 12 & 26 \\
\hline 2011-2015 & 25 & 54 \\
\hline 2016-2020 & & \\
\hline Competency category & 35 & 76 \\
\hline Knowledge & 26 & 57 \\
\hline Technical skills & 8 & 17 \\
\hline 'Non-technical' skills & 67 & 28 \\
\hline Primary educational modality & & 67 \\
\hline Traditional didactics & 13 & 13 \\
\hline Simulation-based training & 31 & \\
\hline E-learning & 6 & \\
\hline
\end{tabular}

Educational outcome (cf. Kirkpatrick's levels ${ }^{13}$

\begin{tabular}{|rrr|}
\hline Level 1 & 8 & 17 \\
\hline Level 2a & 5 & 11 \\
\hline Level 2b & 29 & 63 \\
\hline Level 3 & 1 & 2 \\
Level $4 a$ & 1 & 2 \\
\hline Level $4 b$ & 2 & 4 \\
\hline
\end{tabular}

EVD, Ebola virus disease; H1N1, H1N1 influenza virus infection; MERS, Middle East respiratory syndrome.

\section{Simulation-based training}

In 31 studies $(67 \%)$, simulation-based training (SBT) was an integral part of the training intervention. This ranged from skills stations to practice relevant clinical procedures such as airway management or central venous catheter placement, ${ }^{2738} 63$ to the use of high-fidelity and interactive simulation equipment for large scale scenario training. ${ }^{242744}$ The majority of the studies focused on training of correct use of PPE, while a few studies also used simulation to train interpersonal skills and team training. ${ }^{385658}$ The duration of SBT was variable across studies, ranging from shorter sessions ${ }^{214464}$ to multi-day courses. $^{263336374353}$

\section{Effects and level of educational outcome}

Eight out of forty-six studies (17\%) evaluated the learning outcome at Kirkpatrick level 1, that is, the learners' satisfaction and experience with the training intervention. All these studies concordantly found that learners were satisfied with training regardless of the intervention. 2431374449536062

Modification of attitude or perceptions (Kirkpatrick level 2a) were an outcome in five studies $(11 \%)$. In one of these studies it was reported that the participants felt more confident after the intervention that consisted of 80 hours of lectures and SBT of care and management of the infected patient. ${ }^{27}$

The majority of the studies $(n=29,63 \%)$ reported on modification of knowledge and/or skills (Kirkpatrick level $2 b$ ) resulting from the educational intervention. A significant decrease in number of errors in donning and doffing of PPE was demonstrated in one study after a single 1-hour theoretical session combined with three simulation sessions, which were repeated after 72 hours. ${ }^{28}$ A longer 3-day course of e-learning and SBT regarding safety measures in patient with EVD care reported a significant increase in knowledge scores from pre to post intervention as well as an overall high performance in the simulation scenario on PPE use. ${ }^{36}$

Only one study reported on behavioural change in the clinic among the participants who correctly used PPE after supplemental SBT as compared with the ones who underwent the standard training (Kirkpatrick level 3). ${ }^{45}$ Change in organisational practice (Kirkpatrick level 4a) was reported following SBT in IPC, which led to a decrease in infection rate among HCW. ${ }^{23}$ Two studies included Kirkpatrick level $4 \mathrm{~b}$ evaluation by demonstrating a benefit to patients or clients directly attributable to the training intervention. ${ }^{2356}$ In one of these, decreased mortality rates in ECMO patients was found after implementation of an ECMO training programme $(66.7 \%$ vs $91.3 \%, \mathrm{p}=0.013) .{ }^{56}$

\section{DISCUSSION}

In this systematic review, we identified 46 studies on training and educational interventions for HCW that were developed and implemented due to an ongoing or a recent major viral epidemic.

\section{Target population and characteristics}

Most of the educational interventions were prompted by the urgent need to train HCW, especially in relation to the EVD outbreak, which had the highest case fatality rate at $40.4 \%$ compared with SARS $(9.6 \%)$, MERS $(34 \%)$, H1N1 $(0.02 \%)$ and COVID-19 (3.4\% as of 3 March 2020$).{ }^{67}$ EVD training programmes were initiated for all HCW who were deployed to the frontlines mainly focused on IPC procedures and the proper use of PPE. For the other viral diseases, a surge of critically ill patients with respiratory failure has prompted many of the simulation-based interventions to train critical care management skills such as ACLS/AALS and ECMO. ${ }^{4445356}$ All these high-risk infections also expose HCW to psychological hazards such as fatigue, occupational burnout and distress, furthermore 
highlighting that psychological support to maintain the well-being of HCW during a pandemic is imperative, as seen in a number of studies. ${ }^{34} 626268$

\section{Educational content and competency category}

The use of traditional didactic methods to teach theoretical knowledge is common when a large number of learners need to be targeted at the same time. Depending on the learning goals, theoretical knowledge can be efficiently delivered in less than a day, and brief sessions are particularly efficient if modules are spaced (ie, distributed learning) as demonstrated in several of the included studies. $^{284661}$

The advent of e-learning, including web based and other technology enhanced learning, has opened immense opportunities for flexible dissemination of information notwithstanding time and location. ${ }^{69}$ This poses an advantage, especially for HCW in remote locations, where learning resources can be accessed in their own time and without potential transmission of infection between the learners. E-learning is dependent on online access, which could be a challenge in rural communities with limited network coverage. ${ }^{35}$ In light of COVID-19, the WHO Health Emergencies Programme has launched free online training resources, providing HCW and staff access to real-time knowledge on how to detect, prevent and respond to the new coronavirus. ${ }^{70}$ In medical education, e-learning has been found to have large positive effects and is especially effective when combined with other educational modalities. ${ }^{69}$

SBT has also been increasingly used as an integral part of medical training with positive effects on knowledge, skills and behaviours. ${ }^{71}{ }^{72}$ In the context of a viral outbreak, simulation provides a safe and controlled environment for training of emergency response including teamwork and system readiness. This is corroborated by the included studies on PPE, which found that participants benefitted from repeated training of donning and doffing; of efficiently performing procedures while wearing a constricting PPE; and the use of full-scale scenarios for team-based training. ${ }^{38} 44$

These three major educational strategies can all be used in combination and integrated in a structured curriculum to achieve an optimised learning experience. ${ }^{73}$ Several of the included studies achieved this by using e-learning to provide precourse materials, allowing for self-learning prior to course start, then theoretical teaching through lectures and other interactive learning strategies such as group exercises and discussions, and finally practical skills training in a simulated setting. ${ }^{74}$ Multimodality and extensive training presents a challenge especially for countries with limited resources $;{ }^{75}$ however, standardised training programmes that are supported by the international communities and the local government bodies seem to help alleviate this.

Training delivery and effects and level of educational outcome In the included studies, effect of training varied across educational strategies and mode of evaluation.
Interestingly, duration of the training intervention did not seem to correlate with the relative effect on the educational outcome: for example, a 3-day workshop on EVD management resulted in an increase of correctly answered questions from a preworkshop median of 7 to a postmedian of $9(\sim 29 \% \text { increase })^{26}$; whereas a 3-hour training session on EVD awareness demonstrated an improvement in knowledge from the mean baseline score of 3.93 to a mean score of 13.18 after intervention ( 235\% increase). ${ }^{41}$ This illustrates that training outcome is very much dependent on the objectives of the training and how it is evaluated. It is also important to be critical in regard to the size of the effects of training reported: a 2-hour session on $\mathrm{SARS}^{47}$ reported a statistically significant increase in knowledge; however, the actual change in test scores from pretraining to posttraining intervention was only $3 \%$, and therefore of limited consequence.

Most of the included studies reported outcomes of the educational intervention at the level of learner satisfaction (level 1), modification of attitude (level 2a) and modification of knowledge and skills (level 2b) without evaluating if the training affected clinical practice. Learner satisfaction and attitude are typically measured using postcourse surveys and changes in knowledge and skills by pretraining and posttraining tests. Unsurprisingly, these will almost always result in high levels of satisfaction, increase in confidence and improvement in knowledge and skills after intervention. ${ }^{76}$ Further, these outcomes provide little-to-no information on actual performance and translation into improved performance in the clinical environment and/or patient outcomes. ${ }^{76}$

\section{Implications and perspectives}

The current pandemic has highlighted that despite many relevant training interventions already developed, these seem to not have been widely adapted or implemented. There is a need for structured and evidence-based training programmes that are easily replicated and adaptable to local contexts and settings. ${ }^{18}$ Development of educational interventions should follow a systematic approach such as Kern's six-step model ${ }^{73}$ : starting with a general needs assessment to identify gaps and learner needs; a targeted needs assessment to align to targeted context; definition of goals and objectives including plans for assessment to ensure that the learning goals are met and that learning outcomes are measured appropriately (ie, knowledge and skills transfer into the clinical environment) ${ }^{7778}$; selection of educational modalities, which could include different categories of knowledge, technical skills and 'nontechnical' skills) ${ }^{73}{ }^{79}$; and finally, plans for implementation and evaluation of the training programme.

Training should be optimised and implemented based on learning needs, conditions and resources, allowing for deliberate and distributed practice over time. ${ }^{80}$ Assessment of the effect of learning interventions plays a critical role and ultimately, provides evidence for improved patient outcomes. ${ }^{73} 81$ At present, evidence regarding training and education in preparation for a viral epidemic 
is sparse and not any of the interventions included in this review has followed a structured model for curriculum development nor has undergone rigorous evaluation.

We recommend medical educators to share and publish their actual results or design of educational studies as additional resources in keeping with high standards and to collect evidence for their educational interventions. ${ }^{82}$ To ensure that key information are gathered and reported, the criterion-based checklist that was used in this study can guide the development and implementation of quality educational interventions. Interestingly, we note that scientific studies spike during or shortly after the onset of the viral epidemic and tend to decline after a few years. With more than 61000 studies found in PubMed relating to the 5 viral diseases, less than $6 \%$ relates to education and training and of these, only 46 were educational interventional studies. This further highlights the need for careful planning and refinement of training interventions also post epidemic, by systematically improving educational approach, study design and outcome measures so that these efforts can prepare the medical community best possibly for the next epidemic. Educational research should not solely be performed during an ongoing viral epidemic where the stakes are high and the conditions for teaching and training are far from optimal. We recommend that educational interventional studies such as randomised controlled trials are performed before another pandemic happens in order to gather and establish evidence-based educational practices that will best equip and certify HCW with the competences needed in the front lines.

\section{Strengths and limitations}

A strength of this review is the inclusion of educational interventional studies in the last 20 years, providing an overview of the currently published training programmes for HCW and their evidence. A limitation relates to the exclusion of descriptive studies reporting on the development of training programmes without evaluation. Many of the included studies were not conducted to the highest standards in medical education. We also think that there is a substantial educational effort that goes unreported. Another limitation is the exclusion of nonEnglish language studies which could have helped answer the first research question given that most of the reports concerning viral epidemics come from non-English speaking nations. Finally, we did not include studies that solely evaluated organisational or system-wide impact of interventions because we aimed in this review to focus on how to train HCW rather than how to improve systems through training.

\section{Conclusion}

Published educational interventional studies in relation to training during viral epidemics demonstrate a variety of educational content, design, strategies and modes of delivery. Overall, the included studies consistently reported positive benefits of any structured training intervention including positive effects on confidence and knowledge. However, there are very few studies evaluating that these training efforts transfer into improved clinical performance and better patient outcomes. Development and implementation of evidence-based training programmes that can be easily adapted locally are required for the medical community to be well prepared for the next viral epidemic outbreak.

Acknowledgements The authors sincerely thank Jonathan Lawaetz for developing the data extraction form in RedCap, and for organising the data derived from the system.

Contributors All authors have contributed substantially from conception to writing the final version of the manuscript. All authors (LJN, LR, LK and SA) were involved in the conception and design of the study. LJN and SA performed the systematic search, including review and screening for inclusion, while LR and LK participated in resolution of disagreements. LJN, LR, LK and SA were involved in the analysis, synthesis and interpretation of the data. LJN wrote the first draft of the paper with supervision from SA and reviewed by LR and LK. All authors were involved in the revision of the manuscript for relevant scientific content and have approved the final version of the manuscript. All authors are accountable for the accuracy and integrity of this work.

Funding The authors have not declared a specific grant for this research from any funding agency in the public, commercial or not-for-profit sectors.

Competing interests None declared.

Patient consent for publication Not required.

Ethics approval This review did not involve patients and was therefore exempt from ethical approval according to Danish legislation.

Provenance and peer review Not commissioned; externally peer reviewed.

Data availability statement All data relevant to the study are included in the article or uploaded as supplementary information. An overview of the educational interventional studies included in this systematic review regarding training and education of healthcare workers during viral epidemics including characteristics and general description is uploaded as a supplementary information (Table S1). No additional data available.

Supplemental material This content has been supplied by the author(s). It has not been vetted by BMJ Publishing Group Limited (BMJ) and may not have been peer-reviewed. Any opinions or recommendations discussed are solely those of the author(s) and are not endorsed by BMJ. BMJ disclaims all liability and responsibility arising from any reliance placed on the content. Where the content includes any translated material, BMJ does not warrant the accuracy and reliability of the translations (including but not limited to local regulations, clinical guidelines, terminology, drug names and drug dosages), and is not responsible for any error and/or omissions arising from translation and adaptation or otherwise.

Open access This is an open access article distributed in accordance with the Creative Commons Attribution Non Commercial (CC BY-NC 4.0) license, which permits others to distribute, remix, adapt, build upon this work non-commercially, and license their derivative works on different terms, provided the original work is properly cited, appropriate credit is given, any changes made indicated, and the use is non-commercial. See: http://creativecommons.org/licenses/by-nc/4.0/.

ORCID iD

Leizl Joy Nayahangan http://orcid.org/0000-0002-6179-1622

\section{REFERENCES}

1 Smith KF, Goldberg M, Rosenthal S, et al. Global rise in human infectious disease outbreaks. J R Soc Interface 2014;11:20140950.

2 Peiris JSM, Yuen KY, Osterhaus ADME, et al. The severe acute respiratory syndrome. N Engl J Med 2003;349:2431-41.

3 Coker R. Swine flu. BMJ 2009;338:b1791.

4 Zumla A, Hui DS, Perlman S. Middle East respiratory syndrome. Lancet 2015;386:995-1007.

5 WHO Ebola Response Team, Aylward B, Barboza P, et al. Ebola virus disease in West Africa-the first 9 months of the epidemic and forward projections. N Engl J Med 2014;371:1481-95. 
6 Phelan AL, Katz R, Gostin LO. The novel coronavirus originating in Wuhan, China: challenges for global health governance. JAMA 2020;323:709-10.

7 Fineberg HV. Pandemic preparedness and response-lessons from the H1N1 influenza of 2009. N Engl J Med 2014;370:1335-42.

8 Maxwell DN, Perl TM, Cutrell JB. "The art of war" in the era of coronavirus disease 2019 (COVID-19). Clin Infect Dis 2020.

9 Phua J, Weng L, Ling L, et al. Intensive care management of coronavirus disease 2019 (COVID-19): challenges and recommendations. Lancet Respir Med 2020;8:506-17.

10 Adams JG, Walls RM. Supporting the health care workforce during the COVID-19 global epidemic. JAMA 2020;323:1439-40.

11 Rajakaruna SJ, Liu W-B, Ding Y-B, et al. Strategy and technology to prevent hospital-acquired infections: lessons from SARS, Ebola, and MERS in Asia and West Africa. Mil Med Res 2017;4:32.

12 Xiao J, Fang M, et al. SARS, MERS and COVID-19 among healthcare workers: a narrative review. J Infect Public Health 2020.

13 Xiao Y, Torok ME. Taking the right measures to control COVID-19. Lancet Infect Dis 2020;20:523-4.

14 Algaissi AA, Alharbi NK, Hassanain M, et al. Preparedness and response to COVID-19 in Saudi Arabia: building on MERS experience. J Infect Public Health 2020;13:834-8.

15 Fisher D, Teo YY, Nabarro D. Assessing national performance in response to COVID-19. Lancet 2020;396:653-5.

16 Li L, Xv Q, Yan J. COVID-19: the need for continuous medical education and training. Lancet Respir Med 2020;8:e23.

17 Moher D, Liberati A, Tetzlaff J, et al. Preferred reporting items for systematic reviews and meta-analyses: the PRISMA statement. Ann Intern Med 2009;151:264-9.

18 Meinema JG, Buwalda N, van Etten-Jamaludin FS, et al. Intervention descriptions in medical education: what can be improved? A systematic review and checklist. Acad Med 2019:94:281-90

19 Yardley S, Dornan T. Kirkpatrick's levels and education 'evidence'. Med Educ 2012;46:97-106.

20 Abualenain JT, Al-Alawi MM. Simulation-based training in Ebola personal protective equipment for healthcare workers: experience from King Abdulaziz university hospital in Saudi Arabia. J Infect Public Health 2018;11:796-800.

21 Andonian J, Kazi S, Therkorn J, et al. Effect of an intervention package and teamwork training to prevent healthcare personnel Selfcontamination during personal protective equipment Doffing. Clin Infect Dis 2019;69:S248-55.

22 Bazeyo W, Bagonza J, Halage A, et al. Ebola a reality of modern public health; need for surveillance, preparedness and response training for health workers and other multidisciplinary teams: a case for Uganda. Pan Afr Med J 2015;20:404.

23 Bemah P, Baller A, Cooper C, et al. Strengthening healthcare workforce capacity during and post Ebola outbreaks in Liberia: an innovative and effective approach to epidemic preparedness and response. Pan Afr Med J 2019;33:9.

24 Bredmose PP, Sollid S. From in-situ simulation to SOP development. Acta Anaesthesiol Scand 2015;59:26.

25 Bustamante ND, O'Keeffe D, Bradley D. Targeted interprofessional simulation-based training for safe patient management of Ebola virus disease. Acad Emerg Med 2015;22:S328.

26 Carlos C, Capistrano R, Tobora CF, et al. Hospital preparedness for Ebola virus disease: a training course in the Philippines. Western Pac Surveill Response J 2015;6:33-43.

27 Carvalho E, Castro P, León E, et al. Multi-professional simulation and risk perception of health care workers caring for Ebola-infected patients. Nurs Crit Care 2019;24:256-62.

28 Casalino E, Astocondor E, Sanchez JC, et al. Personal protective equipment for the Ebola virus disease: a comparison of 2 training programs. Am J Infect Control 2015;43:1281-7.

29 Dube D, Addy TM, Teixeira MR, et al. Enhancing student learning on emerging infectious diseases: an Ebola exemplar. Am Biol Teach 2018;80:493-500.

30 Eardley W, Bowley D, Hunt P, et al. Education and Ebola: initiating the cascade of emergency healthcare training. J R Army Med Corps 2016;162:203-6.

31 Eckes EJ, Gutierrez D, Peterson A, et al. Educating health care providers in treatment of patients with Ebola virus disease. Crit Care Nurse 2016;36:e8-13.

32 Ferranti EP, Wands L, Yeager KA, et al. Implementation of an educational program for nursing students amidst the Ebola virus disease epidemic. Nurs Outlook 2016;64:597-603.

33 Jones-Konneh TEC, Murakami A, Sasaki H, et al. Intensive education of health care workers improves the outcome of Ebola virus disease: lessons learned from the 2014 outbreak in Sierra Leone. Tohoku J Exp Med 2017;243:101-5.
34 Klomp RW, Jones L, Watanabe E, et al. CDC's multiple approaches to safeguard the health, safety, and resilience of Ebola responders. Prehosp Disaster Med 2020;35:69-75.

35 Mc Kenna P, Babughirana G, Amponsah M, et al. Mobile training and support (MOTS) service-using technology to increase Ebola preparedness of remotely-located community health workers (CHWs) in Sierra Leone. Mhealth 2019;5:35.

36 MenkinSmith L, Lehman-Huskamp K, Schaefer J, et al. A pilot trial of online simulation training for Ebola response education. Health Secur 2018;16:391-401.

37 Narra R, Sobel J, Piper C, et al. CDC safety training course for Ebola virus disease healthcare workers. Emerg Infect Dis 2017;23:S217-24.

38 O'Keeffe DA, Bradley D, Evans L, et al. Ebola emergency preparedness: simulation training for frontline health care professionals. MedEdPORTAL 2016;12:10433.

39 Otu A, Ebenso B, Okuzu O, et al. Using a mHealth tutorial application to change knowledge and attitude of frontline health workers to Ebola virus disease in Nigeria: a before-and-after study. Hum Resour Health 2016;14:5

40 Phrampus PE, O'Donnell JM, Farkas D, et al. Rapid development and deployment of Ebola readiness training across an academic health system: the critical role of simulation education, consulting, and systems integration. Simul Healthc 2016;11:82-8.

41 Rehman H, Ghani M, Rehman M. Effectiveness of basic training session regarding the awareness of Ebola virus disease among nurses of public tertiary care hospitals of Lahore. J Pak Med Assoc 2020;70:477-81.

42 Sijbrandij M, Horn R, Esliker R, et al. The effect of psychological first aid training on knowledge and understanding about psychosocial support principles: a cluster-randomized controlled trial. Int J Environ Res Public Health 2020;17 doi:10.3390/ ijerph17020484

43 Soeters HM, Koivogui L, de Beer L, et al. Infection prevention and control training and capacity building during the Ebola epidemic in guinea. PLoS One 2018;13:e0193291.

44 Abrahamson SD, Canzian S, Brunet F. Using simulation for training and to change protocol during the outbreak of severe acute respiratory syndrome. Crit Care 2006;10:R3.

45 Carrico RM, Coty MB, Goss LK, et al. Changing health care worker behavior in relation to respiratory disease transmission with a novel training approach that uses biosimulation. Am J Infect Control 2007;35:14-19.

46 Chen P-T, Huang Y-C, Cheng H-W, et al. New simulation-based airway management training program for junior physicians: advanced airway life support. Med Teach 2009;31:e338-44.

47 Lin C-F, Yang C-Y, Lu M-S, et al. Effectiveness of a nosocomial infection control training in improving knowledge in patienthired attendants and outsourced workers in Taiwan. $J$ Nurs Res 2008:16:187-93.

48 Marshall CS, Yamada S, Inada MK. Using problem-based learning for pandemic preparedness. Kaohsiung J Med Sci 2008;24:S39-45.

49 McInnes K, Safian L. Keeping SARS out: an education program for SARS screeners in one Ontario Hospital. J Nurses Staff Dev 2005;21:73-8.

50 Rogers B, Buckheit K, Ostendorf J. Development of competencies for respiratory protection for health care workers. Workplace Health Saf 2019:67:56-67.

51 Wu C-J, Gardner G, Chang AM. Nursing students' knowledge and practice of infection control precautions: an educational intervention. $J$ Adv Nurs 2009;65:2142-9.

52 Adini B, Goldberg A, Cohen R, et al. Impact of pandemic flu training on ability of medical personnel to recognize an index case of avian influenza. Eur J Public Health 2012;22:169-73.

53 Brazzi L, Lissoni A, Panigada M, et al. Simulation-based training of extracorporeal membrane oxygenation during $\mathrm{H} 1 \mathrm{~N} 1$ influenza pandemic: the Italian experience. Simul Healthc 2012;7:32-4.

54 Diaz JV, Lister P, Ortiz JR, et al. Development of a severe influenza critical care curriculum and training materials for resource-limited settings. Crit Care 2013;17:S184-5.

55 Diaz JV, Ortiz JR, Lister P, et al. Development of a short course on management of critically ill patients with acute respiratory infection and impact on clinician knowledge in resource-limited intensive care units. Influenza Other Respi Viruses 2018;12:649-55.

$56 \mathrm{Kim}$ G-W, Koh Y, Lim C-M, et al. The effect of an improvement of experience and training in extracorporeal membrane oxygenation management on clinical outcomes. Korean J Intern Med 2018;33:121-9

57 Maunder RG, Lancee WJ, Mae R, et al. Computer-assisted resilience training to prepare healthcare workers for pandemic influenza: a randomized trial of the optimal dose of training. BMC Health Serv Res 2010;10:72. 
58 Watson CM, Duval-Arnould JM, McCrory MC, et al. Simulated pediatric resuscitation use for personal protective equipment adherence measurement and training during the 2009 influenza (H1N1) pandemic. Jt Comm J Qual Patient Saf 2011;37:515-23.

59 Elcin M, Onan A, Odabasi O, et al. Developing a simulation-based training program for the prehospital professionals and students on the management of middle East respiratory syndrome. Simul Healthc 2016;11:394-403.

60 Hanley ME, Bogdan GM. Mechanical ventilation in mass casualty scenarios. augmenting staff: project XTREME. Respir Care 2008;53:176-88.

61 Mathias C. A Learner-led, Discussion-based elective on emerging infectious disease. Am J Pharm Educ 2015;79:81.

62 Aiello A, Khayeri MY-E, Raja S, et al. Resilience training for hospital workers in anticipation of an influenza pandemic. J Contin Educ Health Prof 2011;31:15-20.

63 Choi GYS, Wan WTP, Chan AKM, et al. Preparedness for COVID-19: in situ simulation to enhance infection control systems in the intensive care unit. Br J Anaesth 2020;125:e236-9.

64 Christensen L, Rasmussen CS, Benfield T, et al. A randomized trial of Instructor-Led training versus video lesson in training health care providers in proper Donning and Doffing of personal protective equipment. Disaster Med Public Health Prep 2020;14:514-20.

65 Zhou T, Huang S, Cheng J, et al. The distance teaching practice of combined mode of massive open online course Micro-Video for interns in emergency department during the COVID-19 epidemic period. Telemed J E Health 2020;26:584-8.

66 Centers for Disease Control and Prevention (CDC). Training for healthcare professionals. Available: https://www.cdc.gov/ coronavirus/2019-ncov/hcp/training.html [Accessed 20 Apr 2020].

67 El Elflein J. Fatality rate of major virus outbreaks in the last 50 years as of 2020. Available: https://www.statista.com/statistics/1095129/ worldwide-fatality-rate-of-major-virus-outbreaks-in-the-last-50years/ [Accessed 1 May 2020].

68 World Health Organization (WHO). Coronavirus disease (COVID-19) outbreak: rights, roles and responsibilities of health workers, including key considerations for occupational safety and health. Available: https://www.who.int/publications-detail/coronavirusdisease-(covid-19)-outbreak-rights-roles-and-responsibilities-ofhealth-workers-including-key-considerations-for-occupationalsafety-and-health [Accessed 24 Apr 2020].
69 Cook DA, Levinson AJ, Garside S, et al. Internet-based learning in the health professions: a meta-analysis. JAMA 2008;300:1181-96.

70 World Health Organization (WHO). Online training as a weapon to fight the new coronavirus. Available: https://www.who.int/newsroom/detail/07-02-2020-online-training-as-a-weapon-to-fight-thenew-coronavirus [Accessed 1 May 2020].

71 McGaghie WC, Issenberg SB, Cohen ER, et al. Does simulationbased medical education with deliberate practice yield better results than traditional clinical education? A meta-analytic comparative review of the evidence. Acad Med 2011;86:706-11.

72 Motola I, Devine LA, Chung HS, et al. Simulation in healthcare education: a best evidence practical guide. AMEE guide No. 82. Med Teach 2013;35:e1511-30.

73 Thomas PA, Kern DE, Hughes MT, et al. Curriculum development for medical education: a six-step approach. JHU Press, 2016.

74 Bjerrum F, Thomsen ASS, Nayahangan LJ, et al. Surgical simulation: current practices and future perspectives for technical skills training. Med Teach 2018;40:668-75.

75 Loignon C, Nouvet E, Couturier F, et al. Barriers to supportive care during the Ebola virus disease outbreak in West Africa: results of a qualitative study. PLoS One 2018;13:e0201091.

76 Norman G, dredging D. salami-slicing, and other successful strategies to ensure rejection: twelve tips on how to not get your paper published. Adv health sci educ 2014;19:1-5

77 Yudkowsky R, Park YS, Downing SM. Assessment in health professions education. Routledge, 2019.

78 Lockyer J, Carraccio C, Chan M-K, et al. Core principles of assessment in competency-based medical education. Med Teach 2017;39:609-16.

79 Alken AP, Fluit C, Luursema J-M. Integrating technical and nontechnical skills in hands-on surgical training. Medical and Surgical Education: Past, Present and Future 2018;1.

80 Ericsson KA, Krampe RT, Tesch-Römer C. The role of deliberate practice in the acquisition of expert performance. Psychol Rev 1993;100:363

81 Bordage G, Harris I. Making a difference in curriculum reform and decision-making processes. Med Educ 2011;45:87-94.

82 Van Der Vleuten PM, Dolmans D, Scherpbier A. The need for evidence in education. Med Teach 2000;22:246-50. 